\title{
Synthesis of a new magnetic-MIP for the selective detection of 1-chloro-2,4-dinitrobenzene, a highly allergenic compound
}

\author{
Rosario Josefina Uzuriaga-Sánchez ${ }^{\mathrm{a}, \mathrm{c}}$, Ademar Wong a , Sabir Khan ${ }^{\text {a }}$, Maria I. Pividori ${ }^{\mathrm{b}}$, \\ Gino Picasso ${ }^{\mathrm{c}, *, 1}$, Maria D.P.T. Sotomayor ${ }^{\mathrm{a}, *, 1}$ \\ a Department of Analytical Chemistry, Institute of Chemistry, State University of São Paulo (UNESP), 14801-970 Araraquara, SP, Brazil \\ b Sensors and Biosensors Group, Department of Chemistry, Autonomous University of Barcelona (UAB), 08193, Bellaterra, Barcelona, Spain \\ ' Laboratory of Physical Chemistry Research, Faculty of Science, National University of Engineering, Av. Tupac Amaru 210, Rimac, Lima, Peru
}

\section{A R T I C L E I N F O}

\section{Article history:}

Received 24 September 2016

Received in revised form 29 November 2016

Accepted 5 December 2016

Available online 9 December 2016

\section{Keywords:}

Biomimetic polymers

Plastic antibodies

Magnetic-MIP

1-Chloro-2,4-dinitrobenzene

Environmental control

Allergenic substances

\begin{abstract}
A B S T R A C T
Molecularly imprinted polymers (MIPs) in combination with magnetic nanoparticles, in a core@shell format, were studied for selective detection of 1-chloro-2,4-dinitrobenzene (CDNB), a powerful allergenic substance. Magnetic nanoparticles were prepared by the co-precipitation method and mixed with oleic acid (OA). This material was then encapsulated in three types of hydrophobic polymeric matrix, poly-(MA-co-EDGMA), poly-(AAco-EDGMA), and poly-(1-VN-co-EDGMA), by the mini-emulsion method. These matrices were used due to their ability to interact specifically with the functional groups of the analyte. Finally, the MIP-CDNB was obtained on the magnetic-hydrophobic surfaces using precipitation polymerization in the presence of the analyte. XRD diffraction patterns suggested the presence of magnetite in the composite and SEM analysis revealed a nanoparticle size between 10 and $18 \mathrm{~nm}$. Under the optimized adsorption conditions, the magnetic-MIP material showed a higher adsorption capacity $\left(5.1 \mathrm{mg} \mathrm{g}^{-1}\right)$ than its non-magnetic counterpart $\left(4.2 \mathrm{mg} \mathrm{g}^{-1}\right)$. In tests of the selectivity of the magnetic-MIP towards CDNB, $\alpha$-values of 2.5 and 10.4, respectively, were obtained for dichlorophenol and $o$-nitrophenol, two structurally similar compounds, and no adsorption was observed for any other non-analogous analyte. The magnetic-MIP and magnetic-NIP were applied using water enriched with $0.5 \mathrm{mg} \mathrm{L}^{-1}$ of CDNB, achieving recovery values of $83.8( \pm 0.8) \%$ and $66( \pm 1) \%$, respectively, revealing the suitability of the material for detection of $\mathrm{CDNB}$.
\end{abstract}

(c) 2016 Elsevier B.V. All rights reserved.

\section{Introduction}

1-Chloro-2,4-dinitrobenzene (CDNB), a recognized substrate of the glutathione-S-transferase (GST) enzyme [1] and an irreversible inhibitor of human thioredoxin reductase, is a highly allergenic substance. In individuals exposed to it, this compound can cause effects ranging from simple skin irritation, which can lead to primary or allergic type dermatitis [2,3], as well as induction of type IV or delayed-type hypersensitivity (DTH) [4,5]. The DTH reactions are mediated by T-cells and monocytes/macrophages, rather than by antibodies. CDNB is used medicinally to assess T-cell activity in patients, providing a useful diagnostic test for immunocompromised patients, as well as to treat warts. In the most severe cases, abnormal T-cell function can result in opportunistic infections, including infection with mycobacteria, fungi, and

\footnotetext{
* Corresponding authors.

E-mail addresses: gpicasso@uni.edu.pe (G. Picasso), mpilar@iq.unesp.br (M.D.P.T. Sotomayor)

${ }^{1}$ These authors contributed equally to this work.
}

parasites associated with syndromes including mucocutaneous candidiasis, tuberculin skin reactions, granulomatous inflammations (sarcoidosis, Crohn's disease), and eye and respiratory irritations [6-10]. CDNB is a toxic xenobiotic that is known to cause oxidative stress and cell death [11]. Its effects on human health make it important to be able to detect and quantify this analyte.

CDNB is used as an algaecide in the coolant water of air-conditioning systems [12], where there is an evidence that sensitization to the compound can occur following persistent exposure to low concentrations or by a single exposure to a high concentration. Such exposures can lead to allergic skin reactions or chronic poisoning [6]. CDNB is also used as a reagent for the detection and determination of pyridine compounds and for the synthesis of many other organic compounds. In light of the adverse effects of CDNB on workers in the chemical industry and the public health sector, as well as in the environment, there is a need for methods capable of sensitive and reliable quantification of this chemical.

CDNB is widely used in quantification of the glutathione-s-transferase enzyme [13-16] and its substrates [17]. However, despite its environmental and health relevance, only very few reports have been 
published concerning CDNB quantification [18]. The present work proposes a novel technique for the selective extraction and efficient preconcentration of CDNB, prior to its subsequent simple quantification using techniques such as UV/Vis spectrometry, HPLC, or any other conventional method.

In recent years, our research group has worked on the development of highly efficient molecularly imprinted polymers (MIPs) for various analytes [19-22], in order to obtain selective and specific materials for the extraction of analytes present at very low concentrations [23-24]. These materials with artificially generated recognition sites are capable of rebinding a target molecule with high selectivity, due to the formation of specific binding sites with shape and functionalities complementary to the analyte [24], acting similarly to natural receptors with antibody-antigen interactions. For this reason, MIPs are also called plastic antibodies [25]. Once their synthesis has been optimized, MIPs can be prepared in a very simple and inexpensive way. In addition, they can operate in a wide range of solution $\mathrm{pH}$, at high temperatures, in high ionic strength solutions, and in organic solvents [26-27]. We [28-30] and other research groups [31-35] have synthesized hybrid materials based on magnetic nanoparticles decorated with MIPs, which have shown high selectivity towards various analytes.

The combination of MIPs and magnetic nanoparticles offers many attractive and innovative possibilities in biomedicine and bioanalysis. Magnetic particles can be coated or modified with biological molecules, enabling manipulation using an external magnetic field [36], and their uses can be extended to other areas, including the analysis of industrial effluents or environmental samples. Among other advantages, these hybrid materials offer enhanced selectivity, durability, and the possibility of reuse [28].

This work describes, for the first time, the preparation of magnetic nanoparticles modified with an MIP selective to CDNB, in a core@shell format (magnetic-MIP). In addition, a systematic study was undertaken to select the functional monomers for the intermediate organic polymeric layer, which was prepared by the mini-emulsion method, before obtaining the magnetic-MIP.

\section{Experimental}

\subsection{Reagents}

All the reagents used were analytical grade. 1-Chloro-2,4-dinitrobenzene $(\mathrm{CDNB})$, ferrous sulfate $\left(\mathrm{FeSO}_{4} \cdot 7 \mathrm{H}_{2} \mathrm{O}\right)$, ferric sulfate $\left(\mathrm{Fe}_{2}\left(\mathrm{SO}_{4}\right)_{3} 9 \mathrm{H}_{2} \mathrm{O}\right)$, oleic acid (OA, 9-octadecenoic acid, $\left.\mathrm{C}_{18} \mathrm{H}_{34} \mathrm{O}_{2}\right)$, sodium dodecyl sulfate (SDS), methyl methacrylate, ethylene glycol dimethacrylate (EGDMA), methacrylic acid (MA), acrylic acid (AA), 1vinylimidazole (1-VN), potassium persulfate, bisphenol A (BPA), acetonitrile, methylene diphenyl diisocyanate-4 (MDI), and phloroglucinol were all purchased from Sigma-Aldrich. Methanol, ethanol, sulfuric acid, acetic acid, and sodium hydroxide $(\mathrm{NaOH})$ were obtained from Synth. Solutions were prepared in electrochemical grade deionized water (resistivity $\geq 18 \mathrm{M} \Omega \mathrm{cm}$ at $25^{\circ} \mathrm{C}$ ).

\subsection{Preparation of supermagnetic magnetite-OA nanoparticles}

Supermagnetic nanoparticles of $\mathrm{Fe}_{3} \mathrm{O}_{4}$ were prepared according to the chemical co-precipitation method by adding a solution of $\mathrm{NaOH}$ $(2.5 \% \mathrm{w} / \mathrm{v})$ to a mixture of iron salts with $\mathrm{Fe}^{2+} / \mathrm{Fe}^{3+}$ molar ratio of $1: 2$, at $80^{\circ} \mathrm{C}$, maintaining a constant $\mathrm{pH} 9$ until the process was complete [37]. Afterwards, the precipitate was collected using a neodymium magnet $(5 \times 5 \times 50 \mathrm{~mm})$, filtered, and washed with deionized water. The magnetite was aged for $24 \mathrm{~h}$ in a dry atmosphere and was then vigorously mixed with oleic acid in a ratio of $1: 3(\mathrm{w} / \mathrm{w})$, in order to coat the magnetite with a single surfactant layer of OA (magnetite-OA nanoparticles). The magnetite-OA nanoparticles were washed with water and ethanol, followed by storage in a desiccator for 3 days to ensure complete removal of solvent [38].
2.3. Encapsulation of magnetite-OA nanoparticles in a polymeric matrix: Influence of the functional monomer on MIP efficiency

The magnetite-OA nanoparticles were first encapsulated in a polymeric matrix, following the procedure described by Valero-Navarro et al. [39]. Evaluation was made of matrices based on three different hydrophobic polymers: poly-(MA-co-EDGMA), poly-(AA-Co-EDGMA), and poly-(1-VN-Co-EGDMA). This approach was based on the different abilities of the functional monomers (FM) to interact with the functional groups of the analyte.

The hydrophobic polymerization was performed by the miniemulsion method, using SDS as surfactant. A $2 \mathrm{~g}$ portion of magnetite-OA was dispersed in $4 \mathrm{~mL}$ of $\mathrm{n}$-hexane/chloroform $(1: 1, \mathrm{v} / \mathrm{v})$ and then added to $450 \mathrm{~mL}$ of deionized water containing $337.5 \mathrm{mg}$ of SDS. This mixture was maintained in an ice-water mixture for $10 \mathrm{~min}$, followed by sonication for $20 \mathrm{~min}$. The resulting emulsion was transferred slowly to a flask containing $1.5 \mathrm{~mL}$ of a mixture of the FM and EGDMA (40:60, w/w), under mechanical agitation. The mixture was stirred for $1 \mathrm{~h}$, after which $180 \mathrm{mg}$ of KPS (potassium persulfate) was added to begin the polymerization. The reaction system was heated at $65^{\circ} \mathrm{C}$ under a $\mathrm{N}_{2}$ atmosphere for $24 \mathrm{~h}$. The product was washed 6 times with deionized water, 5 times with acetone, and 5 times with chloroform, in order to eliminate undesirable moieties. The product, consisting of the hydrophobic FM/EGDMA polymer on the magnetic nanoparticles, was denoted magnetite-poly-(FM-coEDGMA).

\subsection{Synthesis of magnetic-MIP selective to CDNB}

The MIP selective to CDNB was synthesized over the magnetic-hydrophobic surface using precipitation polymerization in the presence of the analyte, forming a core@shell structure (Fig. 1). In this procedure, 1-chloro-2,4-dinitrobenzene $(0.20 \mathrm{mmol})$, bisphenol A $(0.70 \mathrm{mmol})$, MDI ( $0.82 \mathrm{mmol})$, and phloroglucinol $(0.33 \mathrm{mmol})$ were dissolved in a mixture of tetrahydrofuran $(8 \mathrm{~mL})$ and $16 \mathrm{mg}$ of the magnetite-poly(FM-co-EDGMA) $(4.5 \% \mathrm{w} / \mathrm{w})$. This procedure was carried out based on the reports of Dickert [40-41] and other research groups [39,42-43], in which the MIP was based on a polyurethane polymer imprinted with the analyte [41]. To obtain polyurethanes, the synthesis requires a polyol (bisphenol A - 2,2-bis(4-hydroxyphenyl)propane), a diisocyanate (MDI - methylene diphenyl diisocyanate-4), and a diol chain extender (phloroglucinol) [44]. These compounds were therefore used to obtain the MIP based on a polyurethane matrix, with phloroglucinol as an additional cross-linker [45] together with the EDGMA immobilized on the magnetite nanoparticles.

The polymerization process was carried out under continuous mechanical stirring for 2 days, in the dark at room temperature. After the polymerization, the material was washed with methanol/acetic acid $(9: 1, v / v)$ in a Soxhlet extractor and then dried under vacuum for 2 days. The NIP (non-imprinted polymer) used as a control polymer was prepared using the same procedure employed for the MIP, but without the analyte molecule.

\subsection{Characterization of the magnetic-MIPS}

\subsubsection{X-ray diffraction $(X R D)$}

XRD analysis was performed using a Rigaku Miniflex II instrument operated using the following conditions: $\mathrm{Cu} K \alpha$ radiation $(\lambda=$ $1.5418 \AA$ ), $15 \mathrm{~mA}, 30 \mathrm{kV}$, Ni filter, $2 \theta$ scanning range of $5-80^{\circ}$, step size of $0.10^{\circ}$, and step time of $2.5 \mathrm{~s}$. The crystal phases were identified using diffraction data from JCPDS (International Centre for Diffraction Data). The mean crystallite sizes were estimated using the DebyeScherrer equation and the selected peaks were fitted by a Gaussian function. 


\subsubsection{Determination of specific surface area and porosity}

The textural properties were studied by $\mathrm{N}_{2}$ sorption measurements at $77 \mathrm{~K}$ (liquid nitrogen temperature), using a Micromeritics Gemini VII 2390t instrument. Prior to the adsorption experiments, the samples were degassed under vacuum with helium, at $80^{\circ} \mathrm{C}$, for $4 \mathrm{~h}$. The specific surface area was calculated according to the BET method and the pore size distribution was evaluated using the BJH (Barrett-Joyner-Halenda) procedure.

\subsubsection{Scanning electron microscopy (SEM)}

The particle size and surface morphology of the samples were analyzed by field emission gun scanning electron microscopy (FEG-SEM), using a JEOL 7500F instrument.

\subsubsection{Transmission electron microscopy (TEM)}

High-resolution transmission electron microscopy (HR-TEM) analyses were performed using a Philips CM200 instrument with resolution of $1.9 \AA$.

\subsection{Quantification of CDNB by HPLC}

Chromatographic analyses were performed using a Shimadzu 20A liquid chromatograph equipped with an SPD-20A UV/Vis detector, an SIL-20A autosampler, and a DGU-20A5 degasser. Separation was achieved with a Phenomenex Luna C18 column $(250 \mathrm{~mm} \times 4.6 \mathrm{~mm})$, and the chromatography system was controlled by a microcomputer. The analyses were performed in isocratic mode, with a mobile phase composed of a mixture of water:methanol $(40: 60, \mathrm{v} / \mathrm{v})$, at a flow rate of $1.0 \mathrm{~mL} \mathrm{~min}{ }^{-1}$, an injection volume of $20 \mu \mathrm{L}$, and a detector wavelength of $260 \mathrm{~nm}$. CDNB standard solutions were prepared in methanol at concentrations of between 0.1 and $25 \mathrm{mg} \mathrm{L}^{-1}$. A typical chromatogram and a typical analytical curve obtained under these conditions are shown in the Supplementary material (S1 and S2).

\subsection{Binding and selective adsorption experiments}

The binding experiment was carried out by adding $5 \mathrm{mg}$ of MagMIP and Mag-NIP to different glass vials, followed by addition (at $\mathrm{pH} \sim 6$ ) of $3.0 \mathrm{~mL}$ of a solution of CDNB at different concentrations, obtained from a stock solution of the analyte dissolved in methanol. The mixture was submitted to rotary shaking for $120 \mathrm{~min}$. The magnetic polymers were separated from the suspensions using a neodymium magnet and the remaining solutions were filtered through a $0.45 \mu \mathrm{m}$ membrane prior to HPLC analysis (Section 2.6). The binding capacity of the samples $\left(Q_{e}\right)$ was calculated using the following eq. [28]:

$\mathrm{Q}_{\mathrm{e}}=\frac{\left(\mathrm{C}_{\mathrm{o}}-\mathrm{C}_{\mathrm{e}}\right) \mathrm{V}}{\mathrm{m}}$

where $Q_{e}\left(\mathrm{mg} \mathrm{g}^{-1}\right)$ is the experimental equilibrium adsorption capacity, $C_{0}\left(\mathrm{mg} \mathrm{L}^{-1}\right)$ is the initial concentration of analyte, $\mathrm{C}_{\mathrm{e}}$ ( $\mathrm{mg} \mathrm{L}^{-1}$ ) is the equilibrium concentration of analyte, $\mathrm{V}(\mathrm{mL})$ is the volume of solution, and $\mathrm{m}(\mathrm{g})$ is the weight of Mag-MIP or Mag-NIP.

Determination of the selectivity towards CDNB employed competitive adsorption experiments performed using two types of analytes: compounds chemically analogous to CDNB (o-nitrophenol and 3,5-dichlorophenol) and compounds with different natures (4-(4nitrophenylazo)resorcinol, p-dimethylaminoazobenzene, and caffeine). The distribution coefficient $\left(\mathrm{K}_{\mathrm{d}}, \mathrm{mL} \mathrm{g}^{-1}\right)$ and selectivity $(\alpha)$ were calculated using Eqs. (2) and (3), respectively [28]:

$K_{d}=\frac{Q_{e}}{C_{e}}$

$\alpha=\frac{\mathrm{K}_{\mathrm{d}(\mathrm{CDNB})}}{\mathrm{K}_{\mathrm{d}(\text { interferent })}}$
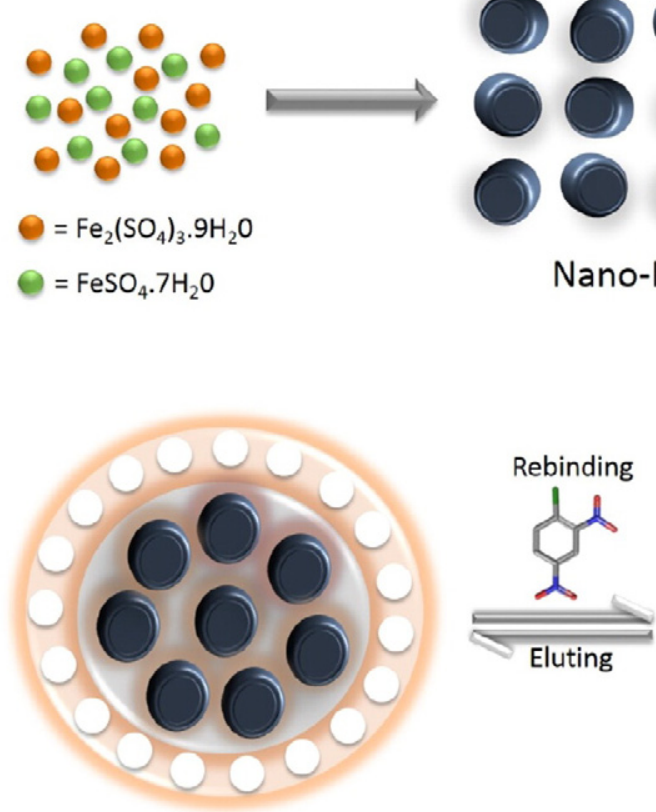

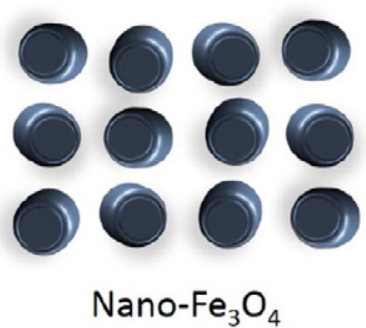

1. Oleic acid

2. SDS

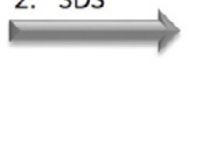

Hydrophobic encapsulation

Poly-(FM-co-EDGMA)

$\mathrm{FM}=\mathrm{MA} ; \mathrm{AA}$ or $1-\mathrm{VN}$.

\section{Core@shell magnetic-MIP}
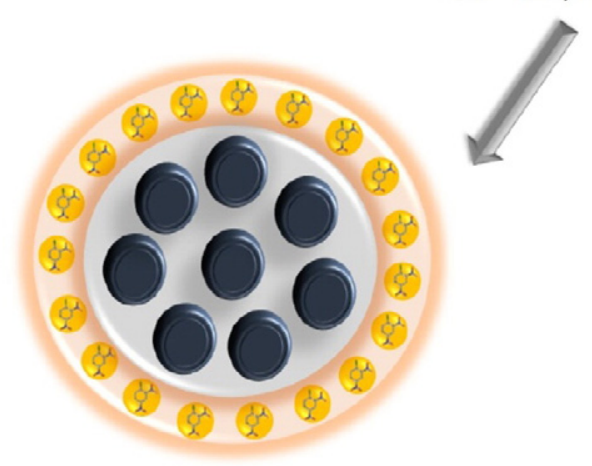

Fig. 1. Schematic representation of the synthesis of the magnetic-MIP for 1-chloro-2,4-dinitrobenzene, proposed in this work. 


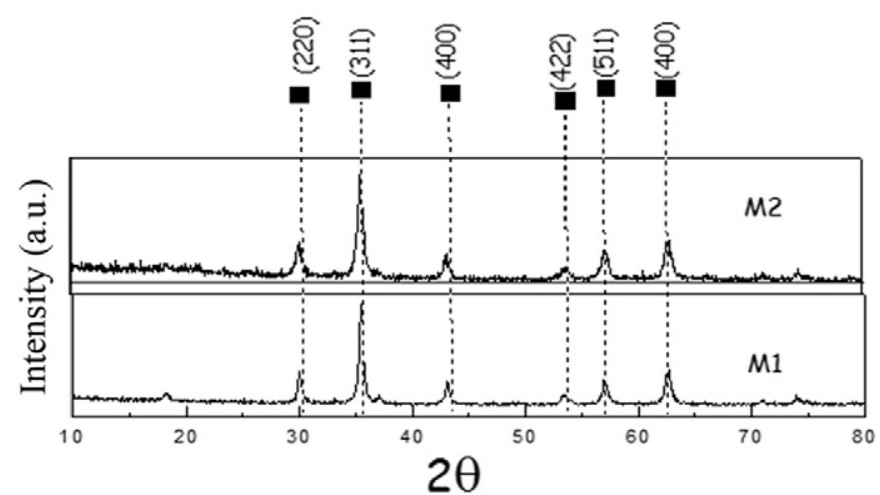

Fig. 2. X-ray diffractograms of the sample prior to reaction with OA (M1) and of the magnetite-OA sample (M2).

\section{Results and discussion}

\subsection{Structural and morphological characterization of the magnetite}

The diffraction patterns of the nanoparticles based on magnetite showed excellent agreement with the characteristic peaks of the magnetite standard (JCPDS file no 19-0629). Fig. 2 shows the diffractograms for the sample prior to reaction with OA (M1) and for the magnetite-OA sample (M2). Peaks corresponding to the diffraction planes (220), (311), (400), (422), (511), and (440) of $\mathrm{Fe}_{3} \mathrm{O}_{4}$ can be seen at angles of $30.19^{\circ}, 35.58^{\circ}, 43.35^{\circ}, 53.57^{\circ}, 56.95^{\circ}$, and $62.70^{\circ}$, respectively, suggesting the presence of a magnetite-like structure as the main component in the composite.

The XRD patterns indicated that the degree of crystallinity of the sample prepared with surfactant (M2) was lower, compared to its counterpart prepared without $\mathrm{OA}$ (M1), as expected due to the anti-agglomeration effect of the surfactant.

The anti-agglomeration effect of oleic acid and the size of the particles were also analyzed by scanning electron microscopy (SEM). Sample M1 showed particles ranging from 20 to $90 \mathrm{~nm}$ in diameter, with the presence of agglomerations of different dimensions (Fig. 3a), while its counterpart sample M2 showed the formation of smaller particles with diameters from 10 to $18 \mathrm{~nm}$ (Fig. 3b). These characteristics indicated the advantageous use of $\mathrm{OA}$ in terms of the homogeneity and uniformity of shape of the magnetite particles.

The surface areas (S) of the M1 and M2 samples were evaluated using the $\mathrm{N}_{2}$ sorption technique, with fitting of the isotherms according to the BET method. As shown in Fig. 4, both samples presented typical type IV isotherms of mesoporous powders, with $\mathrm{H} 1$ and $\mathrm{H} 3$ type hysteresis loops for M1 and M2, respectively. An important finding was that the BET specific surface area of sample M2 was higher than that of sample M1 (Table 1), which could lead to greater MIP formation on the M2

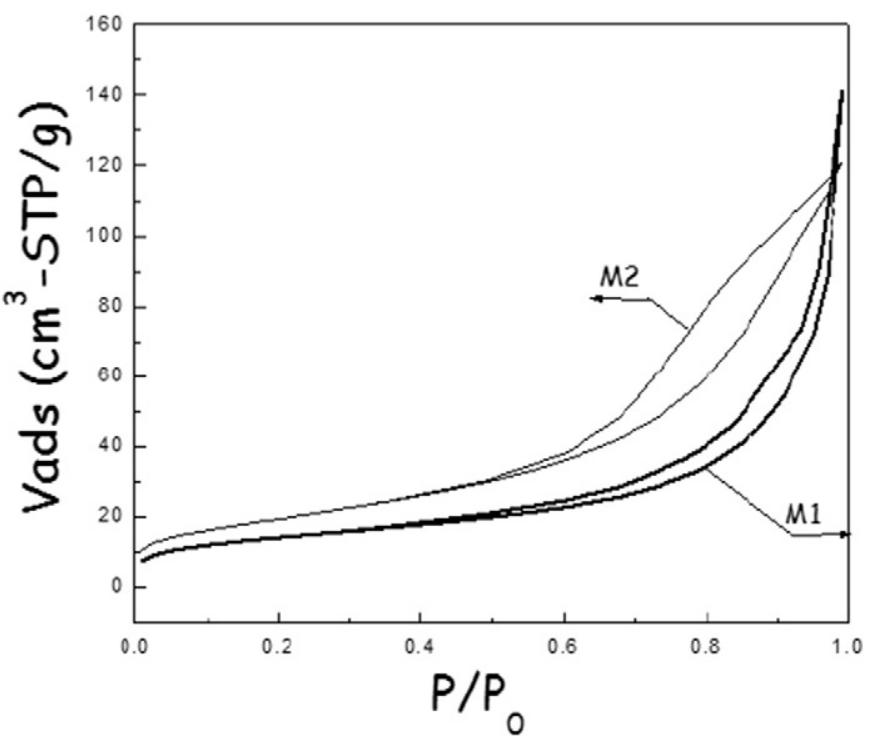

Fig. 4. $\mathrm{N}_{2}$ sorption isotherms of magnetite samples without (M1) and with oleic acid (M2).

surface, hence increasing the number of selective cavities in the magnetic-MIP. As expected, the use of oleic acid as a surfactant resulted in the formation of particles with smaller pore size and higher surface area in the magnetite-OA nanomaterial (Table 1).

3.2. Influence of the functional monomer in the hydrophobic polymeric matrix of poly-(FM-co-EDGMA) on the magnetic-MIP efficiency

In order to identify appropriate conditions for the synthesis of magnetic-MIP, one of the more important parameters, described for the first time in this work, was the interaction of the analyte (1-chloro-2,4-dinitrobenzene) with the functional monomer used in preparation of the MIP. In the preparation of the hydrophobic polymeric matrix, the monomers were not directly used in the presence of the analyte. However, their interaction was very important in the step prior to the MIP synthesis, because the stronger the interaction between the monomer and the solid matrix, the greater the number of selective cavities expected to be formed in the final magnetic-MIP material. In this study, selection was made of three different monomers that have been used previously as functional monomers in MIP synthesis: 1-vinylimidazol (1-VN) [46], methacrylic acid (MA) [47], and acrylic acid (AA) [48]. Fig. 5 shows the efficiency of adsorption of CDNB for the magneticMIPs prepared using each of the three monomers.

It can be seen from Fig. 5 that efficient imprinting of the magneticMIP using a simple monomer system had a strong influence on adsorption of the template used to prepare the hydrophobic polymeric matrix.
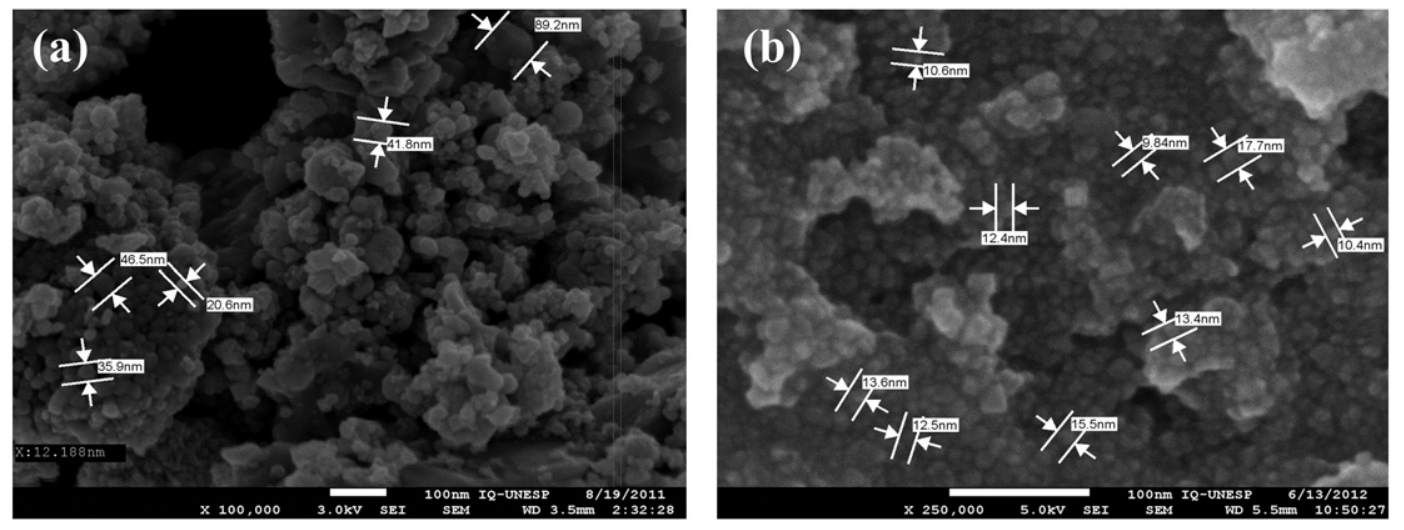

Fig. 3. Scanning electron micrographs of a) the sample without surfactant (M1), at a magnification of $100,000 \times$, and b) magnetite-OA (M2), at a magnification of $250,000 \times$. 
Table 1

BET surface area $(\mathrm{S})$ and pore diameter $\left(\mathrm{d}_{\mathrm{BET}}\right)$ of samples $\mathrm{M} 1$ and $\mathrm{M} 2$.

\begin{tabular}{lll}
\hline Sample & $\mathrm{S}\left(\mathrm{m}^{2} \mathrm{~g}^{-1}\right)$ & $\mathrm{d}_{\text {BET }}(\mathrm{nm})$ \\
\hline M1 & $48.8 \pm 0.2$ & $23.63 \pm 0.08$ \\
M2 & $70.1 \pm 0.3$ & $16.99 \pm 0.03$ \\
\hline
\end{tabular}

The magnetic-MIP synthesized using poly-(MA-co-EDGMA) showed the best adsorption capacity $\left(4.1 \mathrm{mg} \mathrm{g}^{-1}\right)$, with lower values obtained for the magnetic-MIPs prepared using AA and 1-VN (2.0 and $0.9 \mathrm{mg} \mathrm{g}^{-1}$, respectively). This can be explained by the electron-withdrawing nature of the CDNB molecule [49], which generates a strong interaction in the presence of methacrylic acid. The double bond in methacrylic acid and its methacrylate derivatives is highly polarized and its electronic density is decreased due to the electron-withdrawing and resonance effects induced by the carbonyl group [50]. Both methacrylates and acrylates (with lower strength) therefore react readily with nucleophilic reagents such as CDNB. In the present case, a hypothetical interaction between the double bond in methacrylic acid and the nitro groups of the analyte could be considered as an electrostatic interaction. In the case of $1-\mathrm{VN}$, the high electron density caused repulsion of CDNB, which explained the worst results generated using this monomer. Based on these results, subsequent experiments were performed using the magnetic-MIP prepared using methacrylic acid in the hydrophobic layer.

\subsection{Morphological characterization of the magnetic-MIP for CDNB}

Fig. 6 shows TEM micrographs of the magnetic-MIP at two different scales. The agglomeration of magnetite nanoparticles surrounded by the MIP layer can be seen in Fig. 6a. Fig. 6b shows successful formation of the double circle of magnetite@MIP microspheres, with the porous MIP shell uniformly coating the dark $\mathrm{Fe}_{3} \mathrm{O}_{4}$ core. Due to the small size of the magnetite-OA, a greater quantity of recognition sites were formed, so a higher analyte adsorption capacity was expected.

Similar profiles were observed for the corresponding magnetic-NIP (Fig. 7). However, the material was less homogeneous and showed lower porosity (Table 2), due to the absence of selective cavities.

Fig. 8 shows SEM images obtained for the magnetic-MIP at two magnifications. It is evident that the magnetic-MIP presented a homogeneous appearance, with the presence of very well defined spherical microparticles with diameters of up to $900 \mathrm{~nm}$ (Fig. 8b). These microparticles were of different and better shapes, compared to those previously synthesized by us using the precipitation method [28]. This

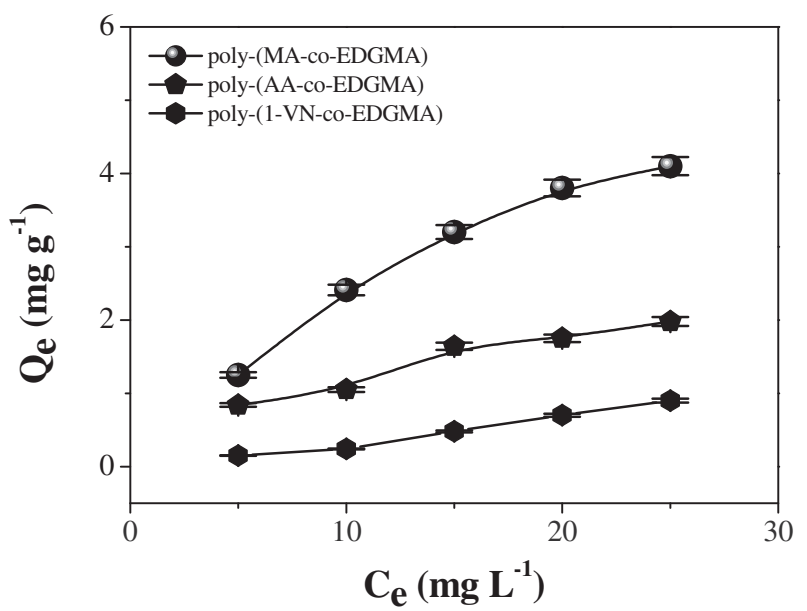

Fig. 5. Adsorption isotherms of the magnetic-MIPs synthesized with hydrophobic polymeric matrices of poly-(MA-co-EDGMA), poly-(AA-Co-EDGMA), and poly-(1-VN-coEDGMA). Measurements were carried out following the procedure described in Section 2.7. (a)

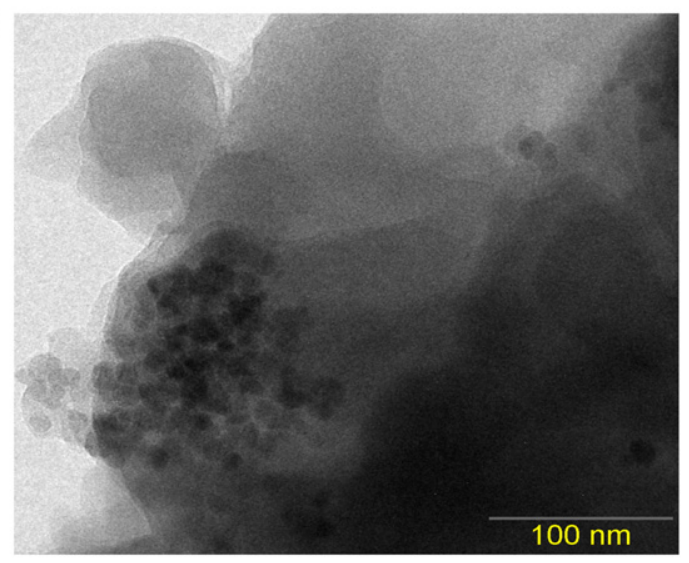

(b)

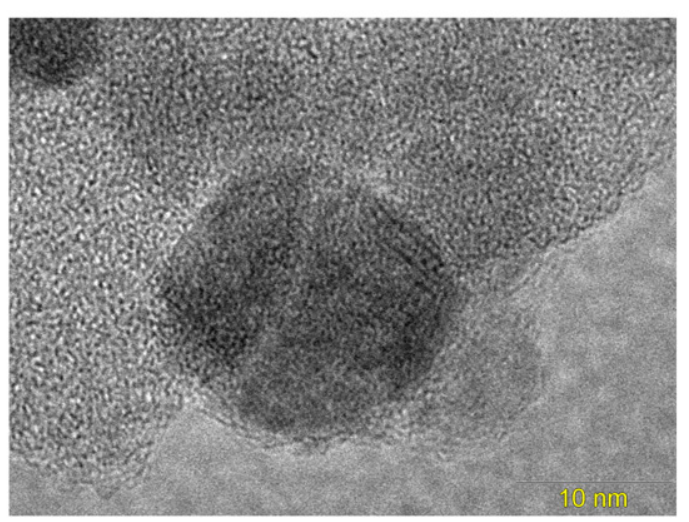

Fig. 6. Transmission electron micrographs of the magnetic-MIP for CDNB at two different magnifications ( $a$ and $b$ ).

(a)

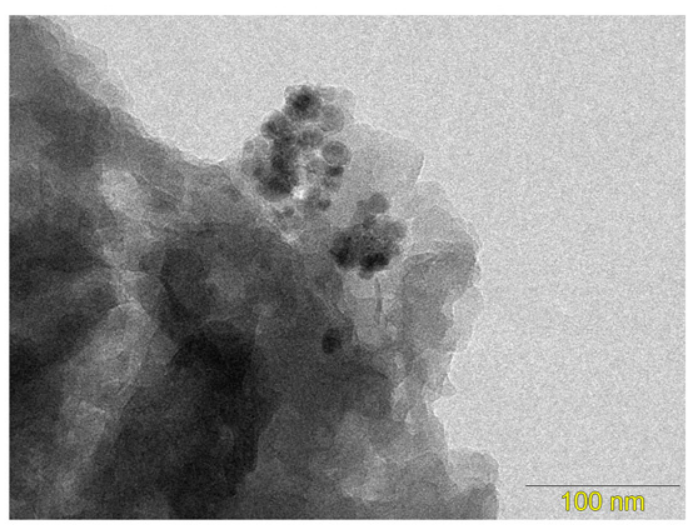

(b)

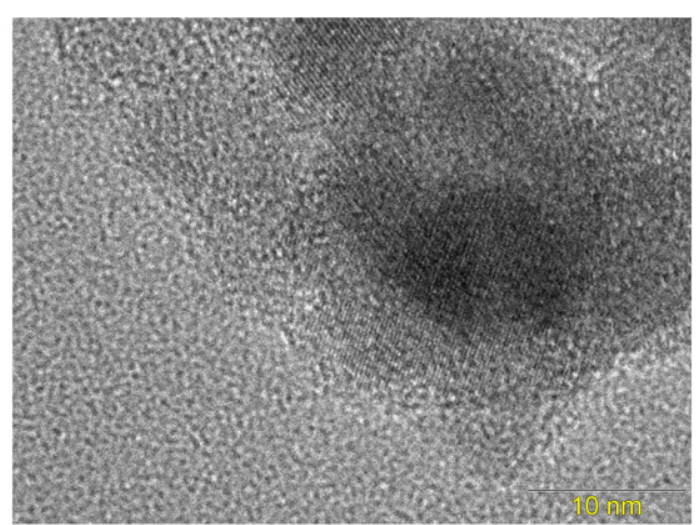

Fig. 7. Transmission electron micrographs of the magnetic-NIP for CDNB at two different magnifications ( $a$ and $b$ ). 
Table 2

BET surface area $(S)$, pore diameter $\left(\mathrm{d}_{\mathrm{BET}}\right)$, and pore volume $\left(\mathrm{V}_{\mathrm{BJH}}\right)$ of the magnetic-MIP and magnetic-NIP samples.

\begin{tabular}{llll}
\hline Sample & $\mathrm{S}\left(\mathrm{m}^{2} \mathrm{~g}^{-1}\right)$ & $\mathrm{d}_{\mathrm{BET}}(\mathrm{nm})$ & $\mathrm{V}_{\mathrm{BJH}}\left(\mathrm{cm}^{3} \mathrm{~g}^{-1}\right)$ \\
\hline Magnetic-MIP & $120.0 \pm 0.6$ & $9.92 \pm 0.04$ & $0.364 \pm 0.001$ \\
Magnetic-NIP & $75.0 \pm 0.5$ & $7.81 \pm 0.02$ & $0.212 \pm 0.002$ \\
\hline
\end{tabular}

revealed that the polymerization method used in this work provided improved synthesis of the magnetic-MIP, compared to other procedures described in the literature $[28,42]$.

The $\mathrm{N}_{2}$-sorption technique was employed to estimate the surface area of the magnetic-MIP and the volume and dimensions of the pores. The surface area of the magnetic-MIP was greater than that of the magnetic-NIP (Table 2). In addition, the data shown in Table 2 indicated that the synthesized materials possessed mesoporous characteristics, as expected for materials based on MIPs. The pore sizes of both materials were $<10 \mathrm{~nm}$, in contrast to the $24 \mathrm{~nm}$ pore size of the magnetite nanoparticles (Table 1), indicating that the MIP layer was present on the surface of the magnetic material, in agreement with the TEM images.

\subsection{Optimization of the adsorption capacity of the magnetic-MIP for CDNB}

The $\mathrm{pH}$ is a very important parameter in adsorption processes because the acidity of the solution can affect the amount of the analyte adsorbed. The extraction of CDNB using the prepared magnetic-MIP was investigated using solutions with different $\mathrm{pH}$ values and the optimal adsorption of CDNB occurred at pH near to 6 (Fig. 9). This could be explained considering the $\mathrm{pK}_{\mathrm{a}}$ values of the analyte and the polyurethane-MIP. It has been found previously that the chain extenders exert a very strong influence on the $\mathrm{pH}$ characteristics of polyurethanes [51]. In this case, the diol chain extender used was phloroglucinol, which has first and second pKa values of 8.0 and 9.2, respectively [52]. At pH between 3.0 and 9.0, the adsorption was almost constant (Fig. 9 ), indicative of favorable interaction between the analyte and the MIP. At these $\mathrm{pH}$ values the polyurethane-MIP was in protonated form and its interaction with the CDNB analyte was maximized, because in this $\mathrm{pH}$ range $\mathrm{CDNB}$ presents high electronic density from nitro and chloride groups, due to its pKa value of 1.8 [53]. This facilitated its transfer into the cavities of the MIP, which was highest at pH 6. The adsorption was lower at $\mathrm{pH}$ above 9.0, at which the two species were negatively charged, introducing a repulsive effect that reduced the analyte-MIP interaction. Hence, pH 6.0 was used in all the subsequent experiments.

Once the optimal pH had been established, evaluation was made of the influence of the sorption time on the retention properties of the

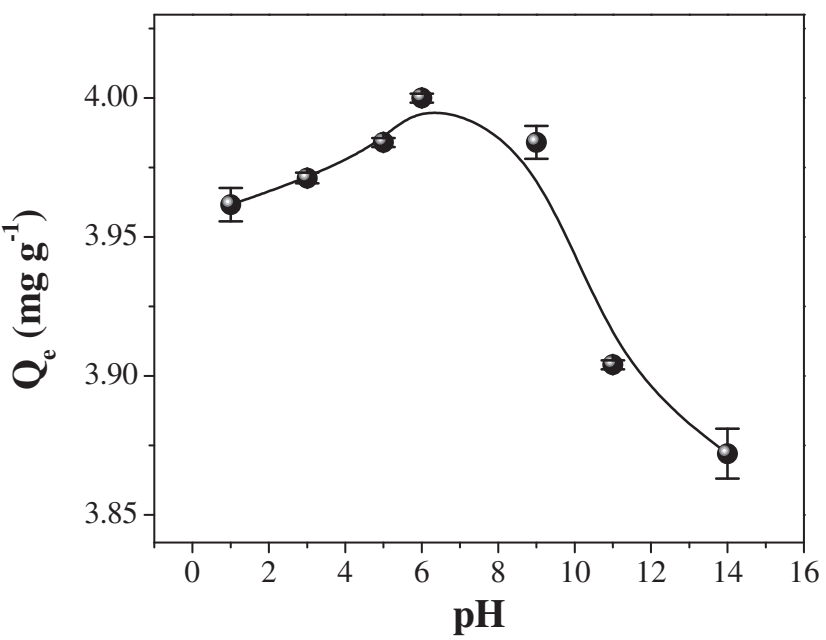

Fig. 9. Influence of $\mathrm{pH}$ on adsorption of 1-chloro-2,4-dinitrobenzene from the extraction solution. Measurements were carried out as described in Section 2.7, with $\mathrm{C}_{\text {analyte }}=$ $10 \mathrm{mg} \mathrm{L}^{-1}$.

MIP. The quantity of CDNB adsorbed by the magnetic-MIP increased with extraction time, up to a maximum at $120 \mathrm{~min}$, after which the adsorption decreased slowly (Fig. 10). Hence, an adsorption time of 120 min was used in the remaining experiments. It is important to point out that the magnetic-MIP always adsorbed greater amounts of CDNB, compared to its corresponding magnetic-NIP counterpart, as shown in Fig. 10. This trend was similar to the behavior of other magnetic-MIPs prepared in our laboratory [29] and could be explained by the different surface areas of magnetic-MIP and magnetic-NIP (Table 2), due to the presence of the selective cavities in the imprinted polymer. An important point to note is that the magnetic-NIP was useful as a control to take account of the non-specific adsorption [30] of CDNB by the magnetic adsorbent material.

\subsection{Selectivity studies}

Experiments to evaluate the selectivity of the prepared magneticMIP were performed for each interfering compound under the previously optimized experimental conditions. Fig. 11 shows the isotherms obtained for two compounds with chemical structures analogous to CDNB, namely 3,5-dichlorophenol (curve b in Fig. 11) and o-nitrophenol (curve $c$ in Fig. 11), compared to the analyte isotherm. The results shown in Fig. 11 enabled estimation of the selectivity of the magneticMIP to CDNB, relative to the interfering compounds. From Eqs. (2) and (3), $\alpha$-values of 2.5 and 10.4 were obtained for 3,5-dichlorophenol
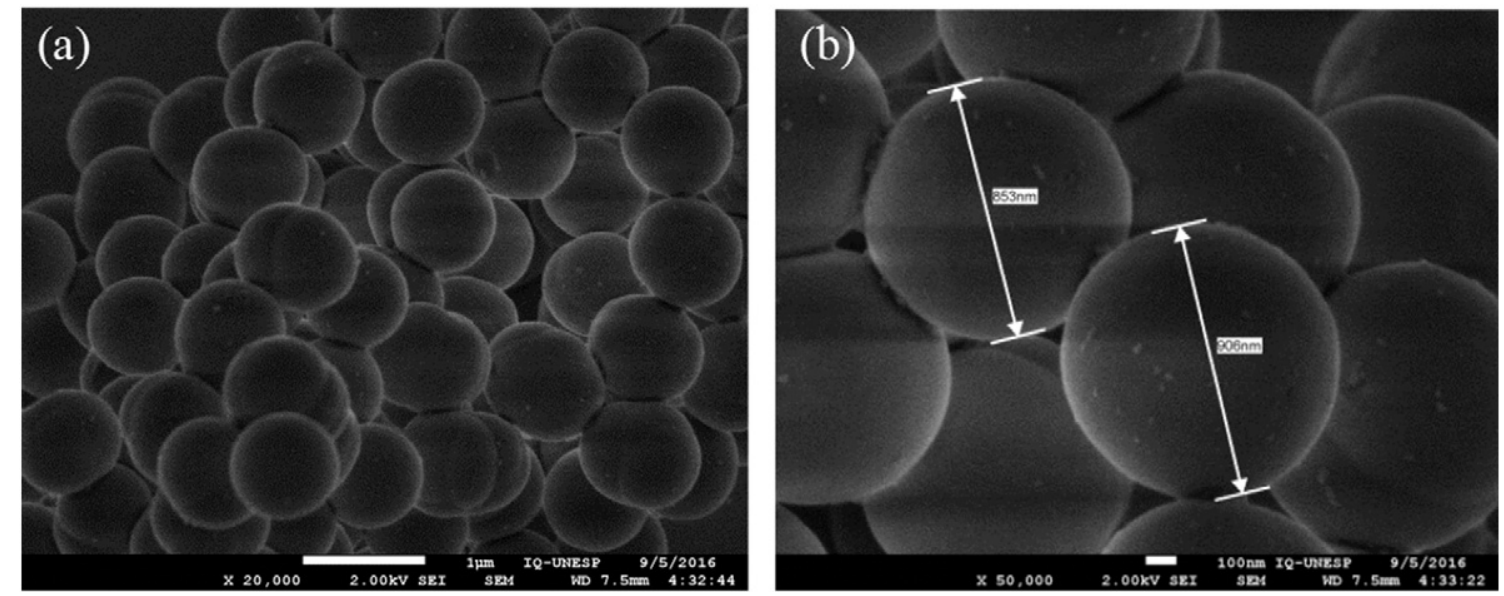

Fig. 8. Scanning electron micrographs of the magnetic-MIP at two different magnifications. 


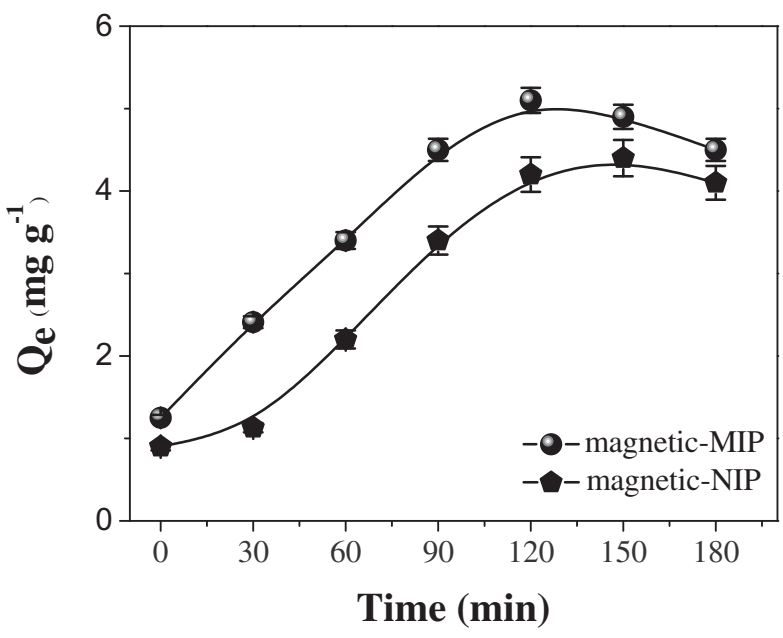

Fig. 10. Time-dependent adsorption of 1-chloro-2,4-dinitrobenzene. Measurements were carried out as is described in Section 2.7, with $C_{\text {analyte }}=10 \mathrm{mg} \mathrm{L}^{-1}$.

and o-nitrophenol, respectively. Hence, even in the presence of compounds with similar chemical structures (Fig. 12), the synthesized magnetic-MIP was highly selective to CDNB.

For other compounds with different structures (Fig. 12), practically no adsorption was observed. The findings of this work therefore indicated that the prepared magnetic-MIP showed a maximum adsorption capacity in the presence of CDNB, due to the presence of nanocavities with selective sizes and the influence of specific sample-receptor interactions.

\subsection{Analytical characteristics and application of the magnetic-MIP}

In order to apply the magnetic-MIP, the HPLC method (Supplementary material S1 and S2) was optimized and showed a broad response range (0.1-25 $\left.\mathrm{mg} \mathrm{L}^{-1}\right)$ together with $\operatorname{LOD}\left(0.03 \mathrm{mg} \mathrm{L}^{-1}\right)$ and retention time (9.1 min) similar to values reported in the literature [18]. Evaluation was then made of the efficiency of the magnetic materials (MIP and NIP) in adsorption and removal of the analyte from tap water enriched with $0.5 \mathrm{mg} \mathrm{L}^{-1}$ of CDNB (Table 3).

As shown in Table 3, the magnetic-MIP showed higher efficiency than the magnetic-NIP in the adsorption of CDNB, together with

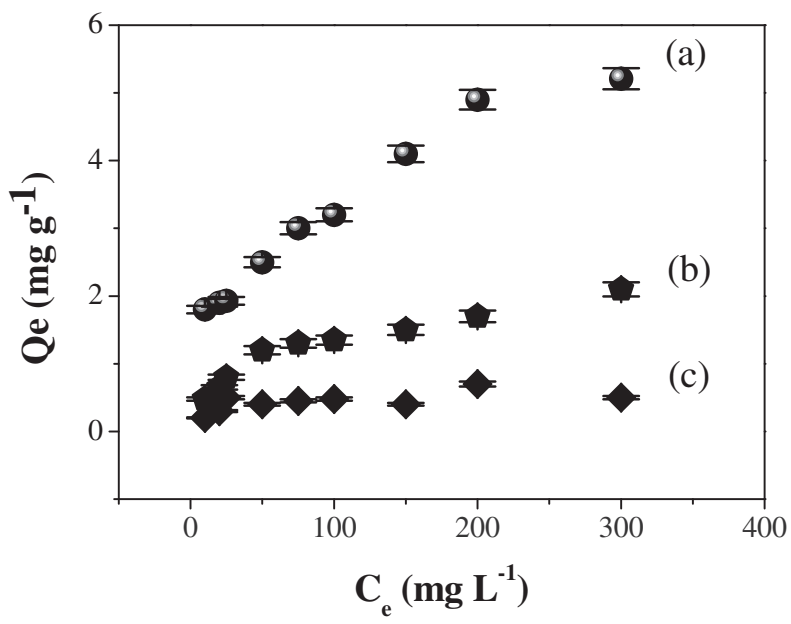

Fig. 11. Adsorption isotherms for (a) 1-chloro-2,4-dinitrobenzene, (b) 3,5-dichlorophenol, and (c) $o$-nitrophenol, obtained under the experimental conditions described in Section 2.7. (a)<smiles>O=[N+]([O-])c1ccc(Cl)c([N+](=O)[O-])c1</smiles>

(b)<smiles>Oc1cc(Cl)cc(Cl)c1</smiles>

(c)<smiles>O=[N+]([O-])c1ccccc1O</smiles>

(e)<smiles>Cn1c(=O)c2c(ncn2C)n(C)c1=O</smiles><smiles>O=[N+]([O-])c1ccc(N=Nc2ccc(O)cc2O)cc1</smiles>

Fig. 12. Chemical structures of (a) 1-chloro-2,4-dinitrobenzene, (b) 3,5-dichlorophenol, (c) o-nitrophenol, (d) 4-(4-nitrophenylazo)resorcinol, (e) caffeine, and (f) pdimethylaminoazobenzene.

complete desorption of the analyte after elution with methanol for $2 \mathrm{~h}$. These results revealed that the magnetic-MIP synthesized in this work is a highly promising material for the recognition and selective removal of the CDNB molecule from water samples.

\section{Conclusions}

This work describes a new magnetic-MIP selective to 1-chloro-2,4dinitrobenzene (CDNB), a powerful allergenic compound that is widely used in various areas and can cause damage to health and the environment. The prepared material exhibited strong magnetic responsiveness, good reproducibility, high adsorption capacity, and excellent selectivity. The magnetic properties of magnetite enabled the direct capture and easy separation of the magnetic-MIP from samples using an external magnetic field. The synthesized material showed good performance, with a high recovery value (near to $84 \%$ ) and satisfactory extraction of CDNB from water samples. In addition, under appropriate conditions (and with the necessary ethical permission), it should be possible to use this material in applications involving biological fluids such as urine.

\section{Acknowledgements}

The authors are grateful for the financial support provided by the Brazilian National Council for Scientific and Technological Development (CNPq), under the Science Without Borders program (processes

Table 3

Recovery values obtained in adsorption and desorption experiments carried out to evaluate the efficiency of the magnetic materials.

\begin{tabular}{lll}
\hline Material & $\mathrm{C}_{\mathrm{CDBN}}=0.5 \mathrm{mg} \mathrm{L}^{-1}$ \\
\cline { 2 - 3 } & Adsorption & Desorption \\
\hline Magnetic-MIP & $83.8 \pm 0.8^{\mathrm{a}}$ & $100 \pm 1$ \\
Magnetic-NIP & $66 \pm 1$ & $63.7 \pm 0.8$ \\
\hline
\end{tabular}


4004759/2012-4 and 303979/2012-7), and InnovatePeru, under the Programa Nacional de Innovación para Competitividad y Productividad (Convenio No 513-INNOVATEPERU-ECIP-2015). R.J.U.S. thanks CAPES (Brazil) for a scholarship. GP acknowledges IGI - Institute of Research of the National University of Engineering.

\section{Appendix A. Supplementary data}

Supplementary data to this article can be found online at http://dx. doi.org/10.1016/j.msec.2016.12.019.

\section{References}

[1] W.B.J. William, H. Habig, J.H. Keen, Glutathione S-transferase in the formation of cyanide from organic thiocyanates and as an organic nitrate reductase, Biochem. Biophys. Res. Commun. 64 (1975) 501-506.

[2] 1-Chloro-2,4-dinitrobenzene (2,4-Dinitro-1-chlorobenzene, DNCB) [MAK Value Documentation, 1999], MAK-Collection Occup. Heal. Saf, Wiley-VCH Verlag GmbH \& Co. KGaA, Weinheim, Germany 2012, pp. 1-115.

[3] S.I. White, P.S. Friedmann, C. Moss, J.M. Simpson, The effect of altering area of application and dose per unit area on sensitization by DNCB, Br. J. Dermatol. 115 (1986) 663-668.

[4] D. Malajian, D.V. Belsito, Cutaneous delayed-type hypersensitivity in patients with atopic dermatitis, J. Am. Acad. Dermatol. 69 (2013) 232-237.

[5] T. Fukuyama, Y. Tajima, H. Ueda, K. Hayashi, T. Kosaka, Prior exposure to immunosuppressive organophosphorus or organochlorine compounds aggravates the T $\mathrm{H}$ 1- and T H 2-type allergy caused by topical sensitization to 2,4dinitrochlorobenzene and trimellitic anhydride, J. Immunotoxicol. 8 (2011) 170-182.

[6] P. Paramasivan, C. Lai, C. Pickard, M. Ardern-Jones, E. Healy, P.S. Friedmann, Repeated low-dose skin exposure is an effective sensitizing stimulus, a factor to be taken into account in predicting sensitization risk, Br. J. Dermatol. 162 (2010) 594-597.

[7] R.J.L.S.N. Irving Sax, Hawley's Condensed Chemical Dictionary, 11th ed. Van Nostrand Reinhold Co, New York, 1987.

[8] NIOSH, NIOSH Pocket Guide to Chemical Hazards, 1990.

[9] E.L.W.J. Hayes, Handbook of Pesticide Toxicology, 1991.

[10] R.J.S. Lewis, Dangerous Properties of Industrial Materials, 2004

[11] S.S. Vaidya, P.M. Gerk, Simultaneous determination of 1-chloro-2,4-dinitrobenzene, 2,4-dinitrophenyl-S-glutathione and its metabolites for human placental disposition studies by high-performance liquid chromatography, J. Chromatogr. B 859 (2007) 94-102.

[12] R.M. Adams, 1-Chloro-2,4-dinitrobenzene as an Algicide, Arch. Dermatol. 103 (1971) 191.

[13] A. Temellini, M. Castiglioni, L. Giuliani, A. Mussi, P.C. Giulianotti, A. Pietrabissa, C.A. Angeletti, F. Mosca, Glutathione conjugation with 1-chloro-2,4-dinitrobenzene (CDNB): interindividual variability in human liver, lung, kidney and intestine, Int. J. Clin. Pharmacol. Ther. 33 (1995) 498-503.

[14] Z.-S. Li, R.-G. Zhen, P.A. Rea, 1-Chloro-2,4-dinitrobenzene-elicited increase in vacuolar glutathione-S-conjugate transport activity, Plant Physiol. 109 (1995) $177-185$.

[15] A.L. Bowman, L. Ridder, I.M.C.M. Rietjens, J. Vervoort, A.J. Mulholland, Molecular determinants of xenobiotic metabolism: QM/MM simulation of the conversion of 1chloro-2,4-dinitrobenzene catalyzed by M1-1 glutathione-s-transferase, Biochemistry 46 (2007) 6353-6363.

[16] B. Coles, M. Yang, N.P. Lang, F.F. Kadlubar, Expression of hGSTP1 alleles in human lung and catalytic activity of the native protein variants towards 1-chloro-2,4-dinitrobenzene, 4-vinylpyridine and (1)-antibenzo[a]pyrene-7,8-diol-9,10-oxide, Cancer Lett. 156 (2000) 167-175.

[17] E.M. Materon, P.-J.J. Huang, A. Wong, A.A.P. Ferreira, M.D.P.T. Sotomayor, J. Liu, Glutathione-s-transferase modified electrodes for detecting anticancer drugs, Biosens. Bioelectron. 58 (2014) 232-236.

[18] S.S. Vaidya, P.M. Gerk, Simultaneous determination of 1-chloro-2,4-dinitrobenzene, 2.4-dinitrophenyl-S-glutathione and its metabolites for human placental disposition studies by high-performance liquid chromatography, J. Chromatogr. B 859 (2007) 94-102.

[19] A. Wong, F.M. de Oliveira, C.R.T. Tarley, M. Del Pilar Taboada Sotomayor, Study on the cross-linked molecularly imprinted poly(methacrylic acid) and poly(acrylic acid) towards selective adsorption of diuron, React. Funct. Polym. 100 (2016) 26-36.

[20] L. Marestoni, A. Wong, G. Feliciano, M. Marchi, C. Tarley, M. Taboada Sotomayo, Optimization and application of imprinted poly(AA-EGDMA) for solid phase extraction of ciprofloxacin in artificial urine, Curr. Drug Ther. 9 (2015) 270-276.

[21] L.D. Marestoni, A. Wong, G.T. Feliciano, M.R.R. Marchi, C.R.T. Tarley, M.D.P.T. Sotomayor, Semi-empirical quantum chemistry method for pre-polymerization rational design of ciprofloxacin imprinted polymer and adsorption studies, J. Braz. Chem. Soc. (2015)

[22] M.V. Foguel, X.-A. Ton, M.V.B. Zanoni, M.D.P.T. Sotomayor, K. Haupt, B. Tse Sum Bui, A molecularly imprinted polymer-based evanescent wave fiber optic sensor for the detection of basic red 9 dye, Sensors Actuators B Chem. 218 (2015) 222-228.
[23] A. Wong, M.V. Foguel, S. Khan, F.M. de Oliveira, C.R.T. Tarley, M.D.P.T. Sotomayor Development of an electrochemical sensor modified with mwcnt-cooh and mip for detection of diuron, Electrochim. Acta 182 (2015) 122-130.

[24] M.J.U. Toro, L.D. Marestoni, M.D.P.T. Sotomayor, A new biomimetic sensor based on molecularly imprinted polymers for highly sensitive and selective determination of hexazinone herbicide, Sensors Actuators B Chem. 208 (2015) 299-306.

[25] S. Yaqub, U. Latif, F.L. Dickert, Plastic antibodies as chemical sensor material for atrazine detection, Sensors Actuators B Chem. 160 (2011) 227-233.

[26] A. Martín-Esteban, Molecularly-imprinted polymers as a versatile, highly selective tool in sample preparation, TrAC Trends Anal. Chem. 45 (2013) 169-181.

[27] C.R.T. Tarley, M.D.P.T. Sotomayor, L.T. Kubota, Polímeros biomiméticos em química analítica. Parte 2: aplicações de MIP ("Molecularly Imprinted Polymers") no desenvolvimento de sensores químicos, Quim Nova 28 (2005) 1087-1101.

[28] R.J. Uzuriaga-Sánchez, S. Khan, A. Wong, G. Picasso, M.I. Pividori, M.D.P.T Sotomayor, Magnetically separable polymer (Mag-MIP) for selective analysis of biotin in food samples, Food Chem. 190 (2016) 460-467.

[29] S. Hussain, S. Khan, S. Gul, M.I. Pividori, M.D.P.T. Sotomayor, A novel core@shell magnetic molecular imprinted nanoparticles for selective determination of folic acid in different food samples, React. Funct. Polym. 106 (2016) 51-56.

[30] A. Ben Aissa, A. Herrera, R.R. Pupin, M.D.P.T. Sotomayor, M.I. Pividori, Magnetic molecularly imprinted polymer for the isolation and detection of biotin and biotinylated biomolecules. Biosens. Bioelectr., In press 2016.

[31] Z. Lin, W. Cheng, Y. Li, Z. Liu, X. Chen, C. Huang, A novel superparamagnetic surface molecularly imprinted nanoparticle adopting dummy template: an efficient solid-phase extraction adsorbent for bisphenol A, Anal. Chim. Acta 720 (2012) 71-76.

[32] A. Mehdinia, T. Baradaran Kayyal, A. Jabbari, M.O. Aziz-Zanjani, E. Ziaei, Magnetic molecularly imprinted nanoparticles based on grafting polymerization for selective detection of 4-nitrophenol in aqueous samples, J. Chromatogr. A 1283 (2013) $82-88$.

[33] D. Xiao, P. Dramou, N. Xiong, H. He, H. Li, D. Yuan, et al., Development of novel molecularly imprinted magnetic solid-phase extraction materials based on magnetic carbon nanotubes and their application for the determination of gatifloxacin in serum samples coupled with high performance liquid chromatography, J. Chromatogr. A 1274 (2013) 44-53.

[34] Y. Li, X. Li, J. Chu, C. Dong, J. Oi, Y. Yuan, Synthesis of core-shell magnetic molecular imprinted polymer by the surface RAFT polymerization for the fast and selective removal of endocrine disrupting chemicals from aqueous solutions, Environ. Pollut. 158 (2010) 2317-2323.

[35] Q.-Q. Gai, F. Qu, Z.-J. Liu, R.-J. Dai, Y.-K. Zhang, Superparamagnetic lysozyme surfaceimprinted polymer prepared by atom transfer radical polymerization and its application for protein separation, J. Chromatogr. A 1217 (2010) 5035-5042.

[36] Y. Hu, J. Pan, K. Zhang, H. Lian, G. Li, Novel applications of molecularly-imprinted polymers in sample preparation, TrAC Trends Anal. Chem. 43 (2013) 37-52.

[37] Y.-H. Deng, C.-C. Wang, J.-H. Hu, W.-L. Yang, S.-K. Fu, Investigation of formation of silica-coated magnetite nanoparticles via sol-gel approach, Colloids Surfaces A Physicochem. Eng. Asp. 262 (2005) 87-93.

[38] C.V. Thach, N.H. Hai, N. Chau, Size controlled magnetite nanoparticles and their drug loading ability, J. Korean Phys. Soc. 52 (2008) 1332.

[39] A. Valero-Navarro, A.L. Medina-Castillo, J.F. Fernandez-Sanchez, A. FernándezGutiérrez, Synthesis of a novel polyurethane-based-magnetic imprinted polyme for the selective optical detection of 1-naphthylamine in drinking water, Biosens. Bioelectron. 26 (2011) 4520-4525.

[40] F.L. Dickert, H. Besenböck, M. Tortschanoff, Molecular imprinting through van der waals interactions: fluorescence detection of PAHs in water, Adv. Mater. 10 (1998) 149-151.

[41] F.L. Dickert, M. Tortschanoff, Molecularly imprinted sensor layers for the detection of polycyclic aromatic hydrocarbons in water, Anal. Chem. 71 (1999) 4559-4563.

[42] A. Valero-Navarro, A. Salinas-Castillo, J.F. Fernández-Sánchez, A. Segura-Carretero, R. Mallavia, A. Fernández-Gutiérrez, The development of a MIP-optosensor for the detection of monoamine naphthalenes in drinking water, Biosens. Bioelectron. 24 (2009) 2305-2311.

[43] A. Valero-Navarro, P.C. Damiani, J.F. Fernández-Sánchez, A. Segura-Carretero, A Fernández-Gutiérrez, Chemometric-assisted MIP-optosensing system for the simultaneous determination of monoamine naphthalenes in drinking waters, Talanta 78 (2009) 57-65.

[44] R.J. Rocha, J.E.S. Lima, S.R. Gomes, K. Iha, J.A.F.F. Rocco, Síntese de poliuretanos modificados por óleo de mamona empregados em materiais energéticos, Quim Nova 36 (2013) 793-799.

[45] I. Sánchez-Barragán, J.M. Costa-Fernández, R. Pereiro, A. Sanz-Medel, Molecularly imprinted polymers based on iodinated monomers for selective room-temperature phosphorescence optosensing of fluoranthene in water, Anal. Chem. 77 (2005) 7005-7011.

[46] F. Zhao, G. Yang, Electrochemical sensor for chloramphenicol based on novel multiwalled carbon nanotubes@molecularly imprinted polymer, Biosens. Bioelectron. 64 (2015) 416-422.

[47] T.S. Anirudhan, S. Alexander, Multiwalled carbon nanotube based molecular imprinted polymer for trace determination of 2,4-dichlorophenoxyaceticacid in natural water samples using a potentiometric method, Appl. Surf. Sc. 303 (2014) 180-186.

[48] A. Ben Aissa, A. Herrera-Chacon, R.R. Pupin, M.D.P.T. Sotomayor, M.I. Pividori, Magnetic molecularly imprinted polymer for the isolation and detection of biotin and biotinylated biomolecules, Biosens. Bioelectron. 88 (2017) 101-108.

[49] B. Bag, P.K. Bharadwaj, Attachment of electron-withdrawing 2,4-dinitrobenzene groups to a cryptand-based receptor for $\mathrm{Cu}(\mathrm{II}) / \mathrm{H}^{+}$-specific exciplex and monomer emissions, Org. Lett. 7 (2005) 1573-1576. 
[50] M.B.C. Araujo, Sobre a polimerização do metacrilato de para-metoxifenila. Porto Alegre: UFRGS, 1996. 162 p. Dissertação (Mestrado em Química) - Programa de Pós-Graduação em Química, Instituto de Química, Universidade Federal do Rio Grande do Sul, Porto Alegre, 1996.

[51] R.B. Trinca, Poliuretanas segmentadas multicomponentes. Campinas: UNICAMP, 2015. 124p. Tese (Doutorado) - Programa de Pós-Graduação em Química, Instituto de Química, Universidade Estadual de Campinas, Campinas, 2015.
[52] D. Wang, K. Hildenbrand, J. Leitich, H.-P. Schuchmann, C. von Sonntag, pH-Dependent tautomerism and pKa values of phloroglucinol (1,3,5-trihydroxybenzene), studied by ${ }^{13} \mathrm{C}$ NMR and UV spectroscopy, Z. Naturforsch. 48b (1993) 478-482.

[53] M.F. Ibrahim, H.A. Abdel-Reheem, S.N. Khattab, E.A. Hamed, Nucleophilic substitution reactions of 2.4-dinitrobenzene derivatives with hydrazine: leaving group and solvent effects, Int. J. Chem. 5 (2013) 33-45. 